\title{
An Intrauterine Pregnancy with Tubo-ovarian Torsion mimicking Ruptured Tubal Ectopic Pregnancy
}

\author{
${ }^{1}$ Navneet Kaur, ${ }^{2}$ Khushpreet Kaur, ${ }^{3}$ Surbhi Saini
}

\begin{abstract}
Aims and objectives: Adnexal torsion is a rare gynecological emergency that requires an early surgical intervention to save the adnexa from irreversible damage. Our study is about the clinical presentation and management of adnexal torsion in a pregnant woman in a tertiary care center.
\end{abstract}

Materials and methods: This case study was done in a pregnant woman who came with adnexal torsion in the first trimester in the labor room of Government Medical College and Patiala, Punjab, India.

Results: Torsion ovarian cyst is found in 5 per 10,000 women in pregnancy. The woman was suspected of having heterotopic pregnancy (an intrauterine pregnancy with ruptured tubal ectopic pregnancy). However, she was diagnosed as intrauterine pregnancy with adnexal torsion during laparotomy.

Conclusion: Adnexal torsion is a rare emergency, which requires a high index of clinical suspicion for diagnosis as the symptoms are nonspecific. Imaging helps in diagnosis, but most of them are diagnosed intraoperatively. Diagnosis is made clinically along with imaging modalities. Ultrasound with color Doppler is the most commonly used imaging modality. An early surgical intervention helps in salvaging the adnexa and prevents further complications.

Keywords: Pregnancy, Torsion, Ultrasound.

How to cite this article: Kaur N, Kaur K, Saini S. An Intrauterine Pregnancy with Tubo-ovarian Torsion mimicking Ruptured Tubal Ectopic Pregnancy. J South Asian Feder Obst Gynae 2017;9(1):56-59.

Source of support: Nil

Conflict of interest: None

Date of received: 16 September 2016

Date of acceptance: 09 January 2016

Date of publication: January 2017

\section{INTRODUCTION}

Adnexal torsion is one of the few gynecological surgical emergencies. Ovarian torsion is defined as partial or complete rotation of the ovarian vascular pedicle

\footnotetext{
${ }^{1}$ Senior Resident, ${ }^{2}$ Professor, ${ }^{3}$ Junior Resident

${ }^{1-3}$ Department of Obstetrics and Gynecology, Government Medical College, Patiala, Punjab, India
}

Corresponding Author: Navneet Kaur, Senior Resident Department of Obstetrics and Gynecology, Government Medical College, Patiala, Punjab, India, Phone: +919780424342 e-mail:nav_neetu8@yahoo.in causing obstruction to venous outflow and arterial inflow. ${ }^{1}$ When fallopian tube also twists with the ovary, it is known as adnexal torsion. ${ }^{2}$ Adnexal torsion mostly occurs in the child-bearing group, but is not uncommon in premenarchal girls or postmenopausal women (including pregnancy). ${ }^{3}$ It is usually associated with a cyst or a tumor, the most common being mature cystic teratoma. Delay or misdiagnosis can result in the loss of the affected ovary and subsequent reduced reproductive capacity. ${ }^{4}$ As the symptoms are nonspecific, it can lead to delay in diagnosing adnexal torsion. Torsion ovarian cyst in pregnancy is very rare, with an incidence of 5 per 10,000 . Ovarian torsion occurs most frequently in the first trimester, occasionally in the second, and rarely in the third. Laboratory investigations and imaging using Doppler scan or magnetic resonance imaging (MRI) help in diagnosis. Torsion of ovary is a dreaded complication leading to infarction, infection, sepsis, peritonitis, and adhesions when treatment is delayed.

\section{CASE REPORT}

A 24-year-old pregnant woman presented to the labor room emergency in the Government Medical College Patiala, Punjab, India on April 3, 2016, at 12:30 pm as G3A2 at 7 weeks 4 days intrauterine pregnancy with right ovarian and tubal torsion. Patient was suspected as a case of heterotopic pregnancy with an intrauterine and a right ruptured ectopic pregnancy.

Patient came with painful abdomen since 5 hours. There was no history of bleeding or any discharge per vaginum. On examination, her vitals were PR 86, blood pressure $118 / 70$, RR 18 , and temperature was $98.4^{\circ} \mathrm{F}$. Cardiovascular, respiratory, and central nervous system examinations were all normal. There was tenderness in right iliac fossa on palpation, but there was no guarding and rigidity on abdominal examination. On bimanual examination, uterus was 6 to 8 weeks size with os closed. A mass of about $4 \times 2 \mathrm{~cm}$ was palpable in the right fornix, which was tender. Left fornix was free and nontender. The urine pregnancy test was again repeated, which was positive.

Urgent ultrasonography (USG) was done in which there was a single live intrauterine G-sac of 7 weeks 4 days with yolk sac and no fetal pole, and a heterogeneous mass of about $5.5 \times 4 \mathrm{~cm}$ in size with cystic areas in the right 
adnexa, not separately defined from right ovary. Left ovary was normally visualized. Final report made on USG was ruptured ectopic pregnancy with intrauterine gestation sac (heterotopic pregnancy).

\section{Investigations}

Hemoglobin $=10.5 \mathrm{gm} \%$, Total leukocyte count $=7,900$, Bleeding time $=1^{\prime} 40^{\prime}$, Clotting time $=2^{\prime} 45^{\prime \prime}$

Prothrombin Index $($ PTI $)=100 \%$, Platelets $=206,000$, Blood urea $=24$, Serum creatinine $=0.8$.

Decision was taken for urgent laparotomy. Intraoperatively, there was a $5 \times 6 \mathrm{~cm}$ torsion right ovarian cyst present with torsion right tube. Tube was congested and edematous. Ovary and tube were both twisted upon itself twice and were gangrenous. No hemoperitoneum was present. Left tube and ovary was normal (Fig. 1). So, right salpingooophorectomy was done and sent for histopathology.

Postoperatively, uterine pregnancy was continued with human chorionic gonadotropin (hCG) and progesterone injections. On the 7 th postoperative day, an
USG was done, which showed a single live intrauterine fetus of 13 weeks 6 days. Fetal heart rate was 160 . Placenta was forming posteriorly. Liquor was adequate. Patient was monitored closely, managed conservatively, and discharged in satisfactory condition on the 9th postoperative day.

A small part of tube was sent for tuberculosispolymerase chain reaction and the report was negative. The holoprosencephaly (HPE) report was suggestive of benign cystic teratoma (dermoid cyst) (Fig. 2).

\section{DISCUSSION}

The torsion ovarian cyst is a rare occurrence in pregnancy. The risk of ovarian torsion rises fivefold during pregnancy. Although the cause of torsion ovarian cyst is not known, most commonly observed adnexal masses associated with pregnancy are functional cysts, dermoid, and serous cystadenomas. ${ }^{5}$ The most frequent complication is torsion. Majority of the adnexal torsions (around two-thirds) are right sided, as the mobility of the left ovary is limited by

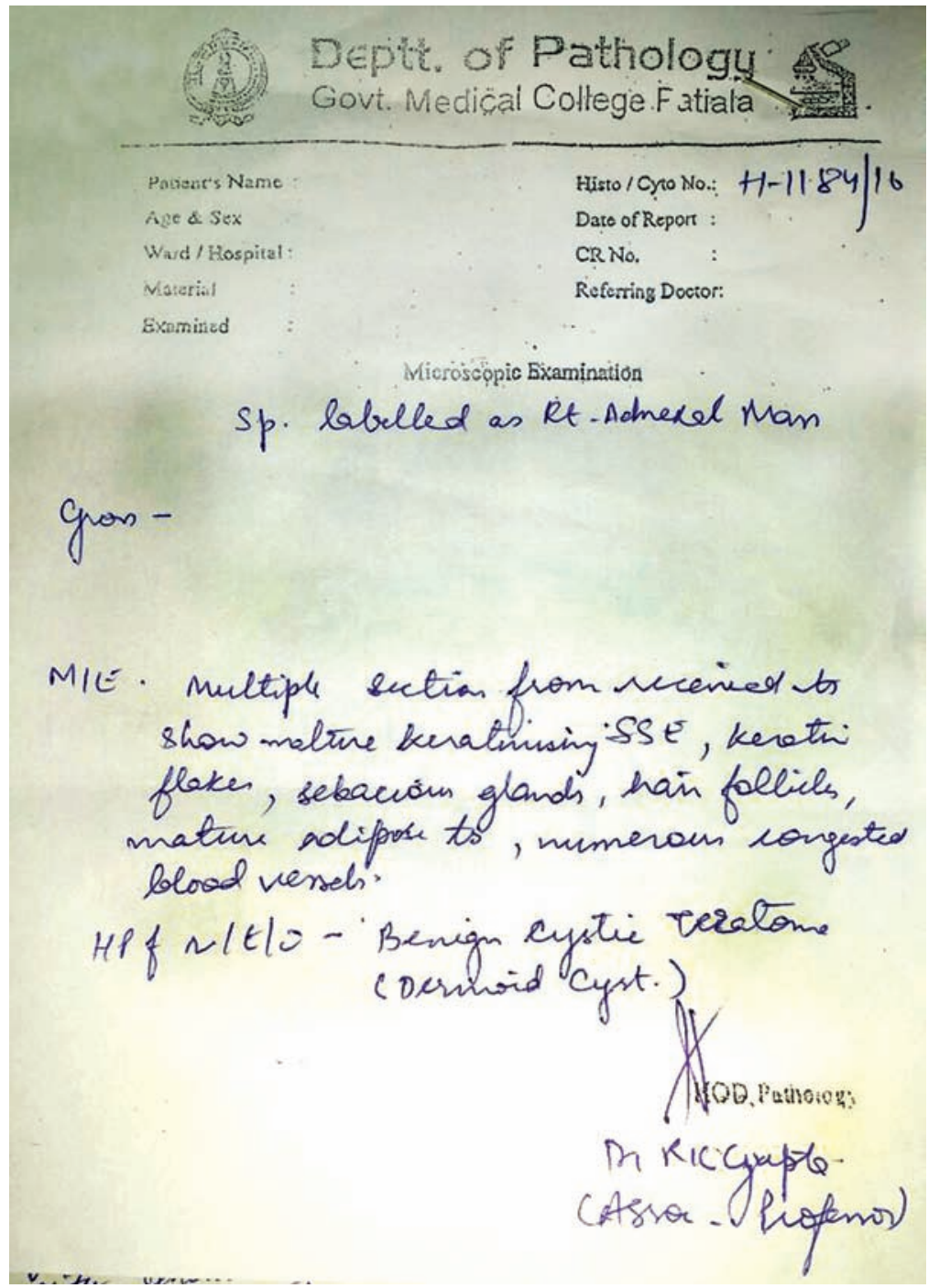

Fig. 1: Holoprosencephaly report 


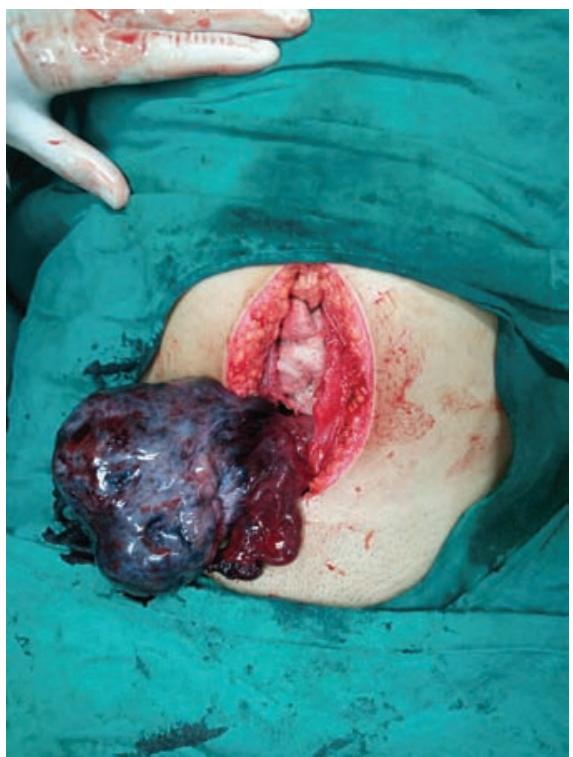

Fig. 2: Torsion tube and ovarian cyst

the sigmoid colon. Most common risk factor for ovarian torsion is ovarian stimulation, as found during early pregnancy or infertility treatment. ${ }^{6}$ Our patient was suspected to have an intrauterine heterotopic pregnancy and ruptured tubal ectopic pregnancy, but it was diagnosed as an adnexal torsion intraoperatively. Such patients usually present with acute severe pain abdomen, and pelvic examination may reveal a tender cystic mass separate from the uterus; similar findings were found in our patient.

Differential diagnosis includes uterine leiomyomas, nonpregnant horn of bicornuate uterus, appendiceal abscess, diverticular abscess, pelvic kidney, retroperitoneal tumors, ectopic pregnancy, and retroverted gravid uterus. Complications of the cysts associated with pregnancy are torsion of the cyst, rupture, infection, malignancy, impaction of cyst in pelvis causing retention of urine, obstructed labor, and malpresentations of the fetus. Incidence of ovarian surgery required in pregnancy is about 1:1,312 pregnancies. Ultrasound should be the first imaging modality of investigation for ovarian mass in pregnant or nonpregnant women. ${ }^{7}$ The MRI can be safely used in pregnancy to evaluate tissue composition and differentiate ovarian mass from other abdominal mass. The clinical significance of cancer antigen 125 tumor marker in epithelial ovarian tumor in pregnancy is less, because it is elevated in the first trimester of pregnancy and declines with advancing gestational age. ${ }^{8}$

Sharma et $\mathrm{al}^{9}$ reported a case of 36 weeks pregnancy with torsion of large right ovarian cyst $(18 \times 10 \times 10 \mathrm{~cm})$ in which cesarean section was done with removal of cyst, which was gangrenous at the time of surgery. The patient had no symptoms and torsion was accidently diagnosed on ultrasound.

Priyadharisini ${ }^{10}$ also reported a similar case of torsion right ovarian cyst of $7 \times 5 \mathrm{~cm}$ in the first trimester of pregnancy at 9 weeks in which laparotomy was done with ovarian cystectomy. Her HPE report showed benign serous cystadenoma of ovary. The patient was managed conservatively thereafter and was followed up and delivered by cesarean section at term.

\section{CONCLUSION}

It is the activity of the reflexes that work for such patients with early suspicion and diagnosis and quick surgical management that can save the life of the patient as well as her pregnancy. However, emergent surgical intervention may be associated with increased risk of adverse outcome for both mother and fetus. Optimal management lies in weighing the risk of expectant management $v s$ intervention in individual cases. Awareness and high level of clinical suspicion of adnexal torsion with imaging help in early diagnosis and appropriate management of the condition. Hence, patients coming in the first trimester with suspicion of ectopic pregnancy should be carefully investigated and managed for good perinatal outcome.

\section{CLINICAL SIGNIFICANCE}

Ovarian masses of 6 to $8 \mathrm{~cm}$ are associated with significantly higher risk of torsion. ${ }^{3}$ Sixty percent of ovarian torsion occurs between 10 and 17 weeks of gestation, and emergency intervention is needed for all cases of torsion to relieve symptoms. Abortion is a common complication of abdominal surgery in the first trimester, and in the second trimester, intrauterine growth restriction and preterm labor can occur. Germ cell tumors are proportionately more common in pregnant women. Of the germ cell tumor markers, lactate dehydrogenase is not altered by pregnancy, but hCG and alpha fetoprotein levels are not reliable during pregnancy. ${ }^{11}$ Expectant management is recommended for most pregnant patients with asymptomatic, nonsuspicious cystic ovarian masses. Surgical intervention during pregnancy is indicated for large and/or symptomatic tumors and those that appear highly suspicious for malignancy on imaging. ${ }^{12}$ Simple cystic masses that are $<6 \mathrm{~cm}$ do not require laparotomy during pregnancy as the risk of malignancy is below $1 \% .{ }^{13}$ If ovarian mass persists into the second trimester and it is $>8 \mathrm{~cm}$, rapidly growing, or a complex mass suspicious of malignancy, surgery should be performed. ${ }^{14}$

\section{ACKNOWLEDGMENT}

The author is highly thankful to all his teachers and his family who encouraged him in every aspect of his life. The author is also thankful to Dr Khushpreet Kaur who helped him in collecting the material and writing this topic. This article has been possible due to the joint effort 
of his coauthors as well. The author really appreciates the work of juniors who helped him in this topic a lot. This study has been conducted after taking informed consent from the patient and it has not inflicted any harm upon the patient involved in the study.

\section{REFERENCES}

1. Nair S, Joy S, Nayar J. Five year retrospective case series of adnexal torsion. J Clin Diagn Res 2014 Dec;8(12):9-13.

2. Growdon WB, Laufer MR. Ovarian and fallopian tube torsion. Uptodate 2013;4:1-18.

3. Oelsnar G, Shashar D. Adnexal torsion. Clin Obstet Gynecol 2006 Sep;49(3):459-463.

4. Damigos E, Johns J, Ross J. An update on the diagnosis and management of ovarian torsion. Obstet Gynaecol 2012 Oct;14(4):229-236.

5. Ali MK, Abdelbadee AY, Shazly SA, Abbas AM. Adnexal torsion in the first trimester of pregnancy: a case report. Middle East Fertility Society J 2013 Dec;18(4):284-286.

6. Morton MJ, Masterson M, Hoffmann B. Case report: ovarian torsion in pregnancy - diagnosis and management. J Emerg Med 2013;45(3):348-351.
7. Valentin L. Use of morphology to characterize and manage common adnexal masses. Best Pract Res Clin Obstet Gynaecol 2004 Feb;18(1):71-89.

8. Condous G, Kirk E, Syed A, Van Calster B, Van Huffel S, Timmerman D, Bourne T. Do levels of serum cancer antigen 125 and creatine kinase predict the outcome in pregnancies of unknown location? Hum Reprod 2005 Dec;20(12):3348-3354.

9. Sharma G, Supe P, Kore SJ, Nandanwar YS. Ovarian torsion at term pregnancy - a rare case report. JPGO 2015;2(12):[1 p].

10. Priyadharisini KS. Torsion of ovarian cyst in first trimester of pregnancy: a case report. J Reprod Infertil 2014;5(3):76-77.

11. Bignardi T, Condous G. The management of ovarian pathology in pregnancy. Best Pract Res Clin Obstet Gynecol 2009 Aug;23(4):539-548.

12. Leiserowitz GS. Managing ovarian masses during pregnancy. Obstet Gynecol Surv 2006 Jul;61(7):463-470.

13. Swensen, RE.; Goff, BA.; Koh, WJ. Cancer in the pregnant patient. In: Hoskins, WJ.; Perez, CA.; Young, RC., editors. Principles of gynecologic oncology. Philadelphia: Lippincott Williams \& Wilkins, 2005. p. 1279-1311.

14. Cunningham FG, Lenovo KJ, Bloom SL, Spong CY, Dashe JS, Hoffman BL, Casey BM, Sheffield JS. Williams obstetrics. 24th ed. New York, NY: McGraw Hill; 2014. p. 1090-1092. 